\title{
Enhanced Performance of Nanowire-Based All-TiO 2 Solar Cells using Subnanometer-Thick Atomic Layer Deposited ZnO Embedded Layer
}

\author{
Amir Ghobadi $^{\text {a,b }}$, Halil I. Yavuz ${ }^{\text {c,d }}$, T. Gamze Ulusoy ${ }^{\text {b,e }}$, K. Cagatay Icli ${ }^{\text {c,d }}$, \\ Macit Ozenbas $^{\mathrm{c}, \mathrm{d}}$, Ali K. Okyay ${ }^{\mathrm{a}, \mathrm{b}, \mathrm{e}, *}$ \\ a Department of Electrical and Electronics Engineering, Bilkent University, Ankara 06800, Turkey \\ b UNAM-National Nanotechnology Research Center, Bilkent University, Ankara 06800, Turkey \\ ${ }^{\mathrm{c}}$ Dept. of Metallurgical and Materials Engineering, Middle East Technical University, Ankara 06800, Turkey \\ d Center for Solar Energy Research and Applications (GUNAM), Middle East Technical University, Ankara 06800, Turkey \\ e Institute of Materials Science and Nanotechnology, Bilkent University, Ankara 06800, Turkey
}

\section{A R T I C L E IN F O}

\section{Article history:}

Received 6 November 2014

Received in revised form 10 January 2015

Accepted 18 January 2015

Available online 20 January 2015

\section{Keywords:}

solar cells

photovoltaic

photoelectrochemical

interface engineering

titanium dioxide

atomic layer deposition

\begin{abstract}
A B S T R A C T
In this paper, the effect of angstrom-thick atomic layer deposited (ALD) $\mathrm{ZnO}$ embedded layer on photovoltaic (PV) performance of Nanowire-Based $\mathrm{All}_{-} \mathrm{TiO}_{2}$ solar cells has been systematically investigated. Our results indicate that by varying the thickness of $\mathrm{ZnO}$ layer the efficiency of the solar cell can be significantly changed. It is shown that the efficiency has its maximum for optimal thickness of 1 ALD cycle in which this ultrathin $\mathrm{ZnO}$ layer improves device performance through passivation of surface traps without hampering injection efficiency of photogenerated electrons. The mechanisms contributing to this unprecedented change in PV performance of the cell have been scrutinized and discussed.
\end{abstract}

(c) 2015 Elsevier Ltd. All rights reserved.

\section{Introduction}

The projected growth of the silicon photovoltaic (PV) industry has been limited due to the material and manufacturing costs. Over the past decades, considerable studies were focused on finding alternative PV technologies which can offer low cost, mature processing technology together with high efficiencies. $\mathrm{TiO}_{2}$ nanowire (NW) template-based hybrid solar cell structures are one of these alternatives because of its excellent optoelectronic and chemical properties in addition to providing high specific surface area, better electron transport and ability to strongly scatter light [1]. The n-type high band gap metal oxide such as $\mathrm{TiO}_{2} \mathrm{NWs}$ array has been extensively utilized as the electron transport layer in a wide range of solar cells such as hybrid solar cells, dye-sensitized solar cells [2] and organic solar cells [3]. Recently, in order to provide better absorption of light over the whole solar spectrum, different kind of semiconductors with higher absorption coefficients such as CdS [4,5], CdSe [6,7], CdTe [8-10], PbS [11] have

\footnotetext{
* Corresponding author at: Department of Electrical and Electronics Engineering, Bilkent University, Ankara 06800, Turkey.

E-mail address: aokyay@ee.bilkent.edu.tr (A.K. Okyay).
}

been used to sensitize metal oxide anode in solid/liquid state quantum dot/semiconductor sensitized solar cells. However, the functionality of semiconductor interfaces plays a crucial role in all hybrid solar cells in which trapping or recombination of charge carriers can reduce PV efficiency. In addition to photovoltaic applications, these interfaces have a great influence on the performance of photoelectrochemical and photocatalytic applications such as water splitting in which a better charge separation, transport and collection can be provided through the engineering of the semiconductors surface [12-14]. Controlling the impact of surface or interface-derived electronic states is, therefore, a prime goal in modern semiconductor processing. To this end, utilization of an interfacial semiconductor, typically a metal oxide with high energy band gap, layer is commonly employed $[8,15,16]$. However, the main drawback associated with such an interfacial layer is the fact that just a couple of nanometers of such a layer can significantly hamper injection efficiency. Therefore, an ultrathin homogeneous coating around the whole surface of NW is required. Among numerous methods available for the deposition of this passivation layer, atomic layer deposition (ALD) is able to coat pinhole-free metal-oxide films with angstrom-scale thickness.

Herein, we demonstrate that ALD coated ZnO embedded layer can efficiently passivate the NWs surface. Although the bare 


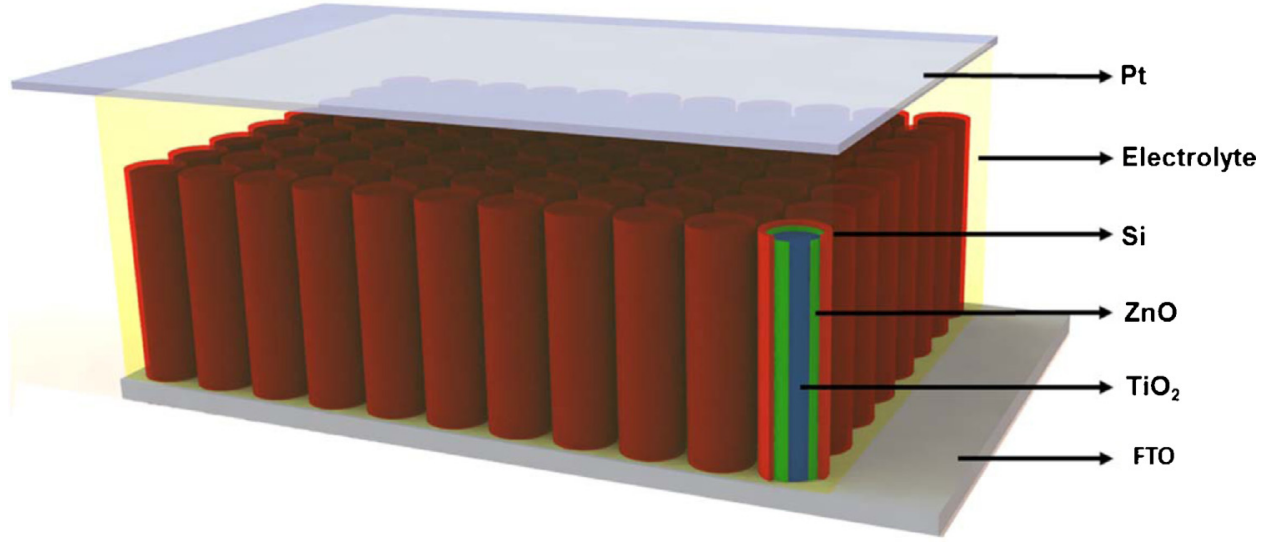

Fig. 1. (a) The 3D schematic of proposed $\alpha-\mathrm{Si} / \mathrm{ZnO} / \mathrm{TiO}_{2} \mathrm{HJ}$ solar cell.

structure (no $\mathrm{ZnO}$ interfacial layer) shows poor efficiency, device performance is boosted remarkably using the $\mathrm{ZnO}$ interfacial layer. With this in mind, the thickness of this interfacial layer plays a crucial role in solar cell performance, in that thicker layers of such a high band gap material impede the electron injection noticeably. It is demonstrated that an optimized ultrathin layer paves the way to efficient devices by reducing recombination at the interface without hampering electron injection capability. It should be
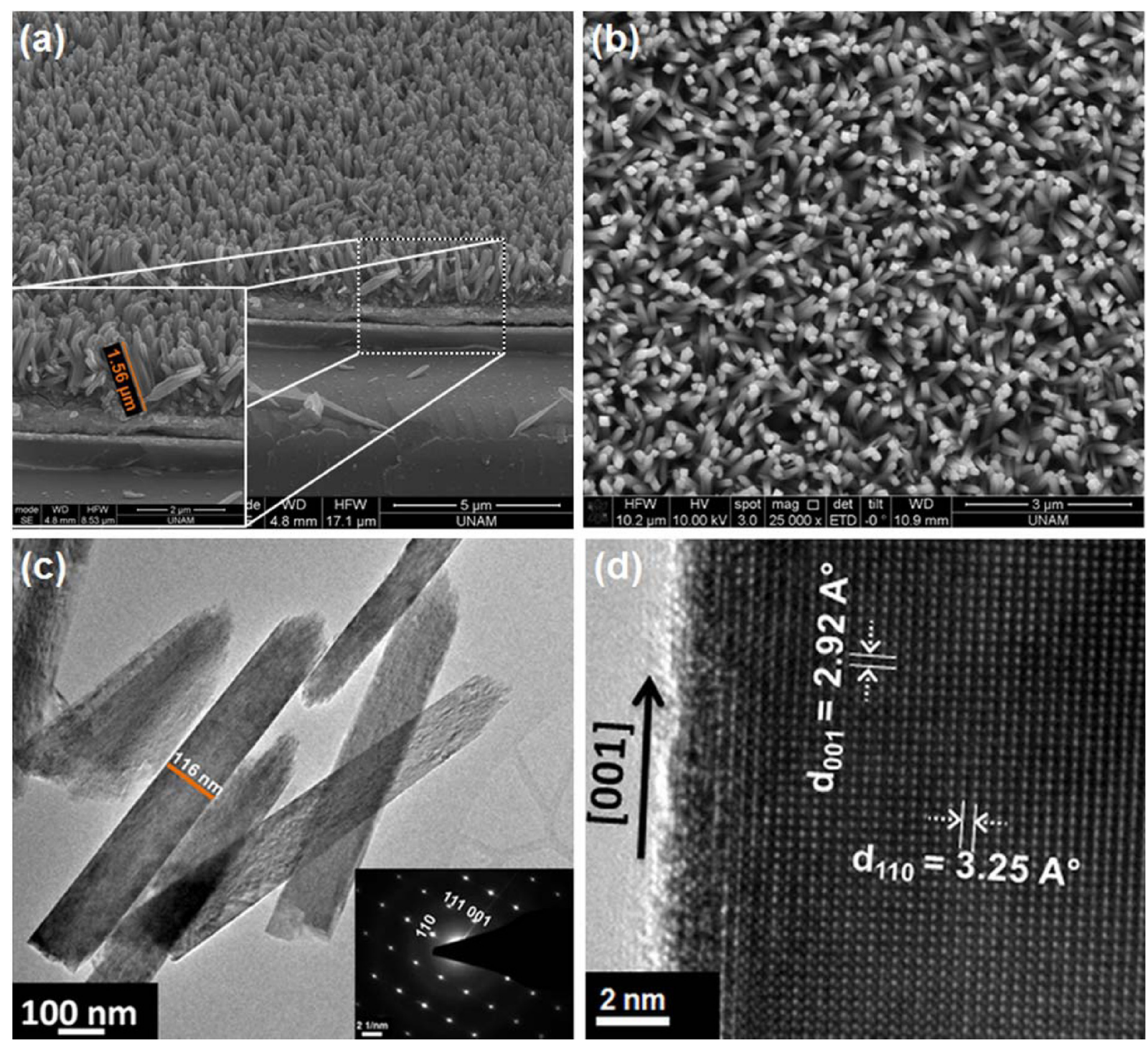

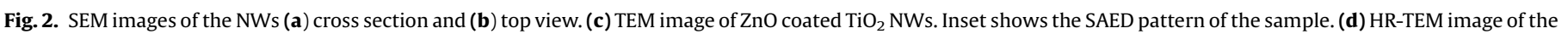
NWs showing the direction of growth and lattice spacing. 

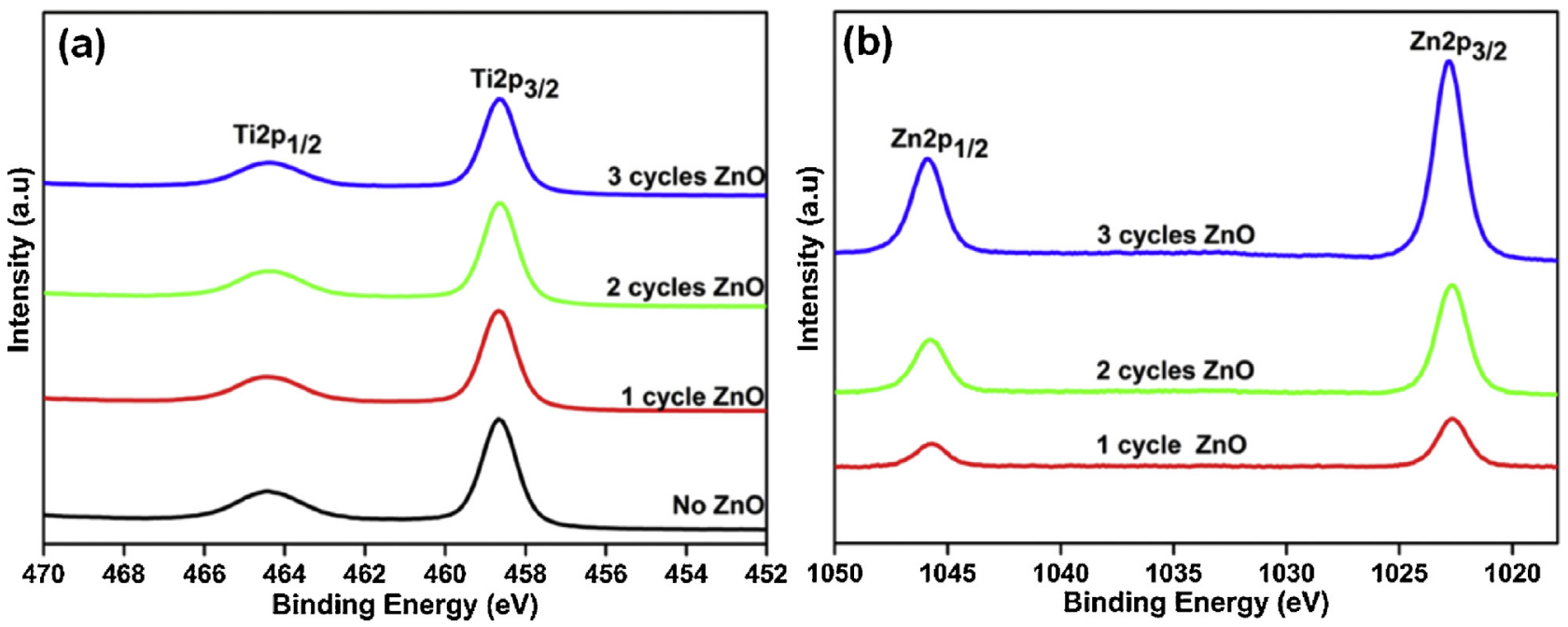

Fig. 3. XPS spectra of (a) $\mathrm{Ti} 2 \mathrm{p}$ and (b) $\mathrm{Zn} 2 \mathrm{p}$ are taken on the surface of $\mathrm{TiO}_{2}-\mathrm{ZnO}$ core-shell NWs.

noted that this modification on $\mathrm{TiO}_{2}$ photoanode surface will improve device performance regardless of the material used as the absorbing layer. It will be discussed that the obtained results are not only promising for PV technology but also they can provide a substantial improvement in the future performance-enhanced photoelectrochemical and photocatalytic cells such as water splitting in which an ultrathin shell layer is desirable for minimizing minority carriers diffusion path while improving charge separation and reducing the recombination rates at the interface. In order to prove the effectiveness of this idea in the photovoltaic performance enhancement, a thin layer of amorphous $\mathrm{Si}(\alpha-\mathrm{Si})$ is used as absorbing layer on $\mathrm{TiO}_{2} \mathrm{NWs}$ and liquid electrolyte as a hole conductor layer. The impact of $\mathrm{ZnO}$ interfacial layer thickness on PV parameters such as open circuit voltage and short circuit current is investigated and discussed.

\section{Experimental procedure}

\subsection{Chemicals}

Ethanol, acetone, titanium butoxide $\left(\mathrm{Ti}\left(\mathrm{OCH}_{2} \mathrm{CH}_{2} \mathrm{CH}_{2} \mathrm{CH}_{3}\right)_{4}\right)$ (97\%) and hydrochloric acid $\mathrm{HCl}$ (36\%) are all from Sigma-Aldrich

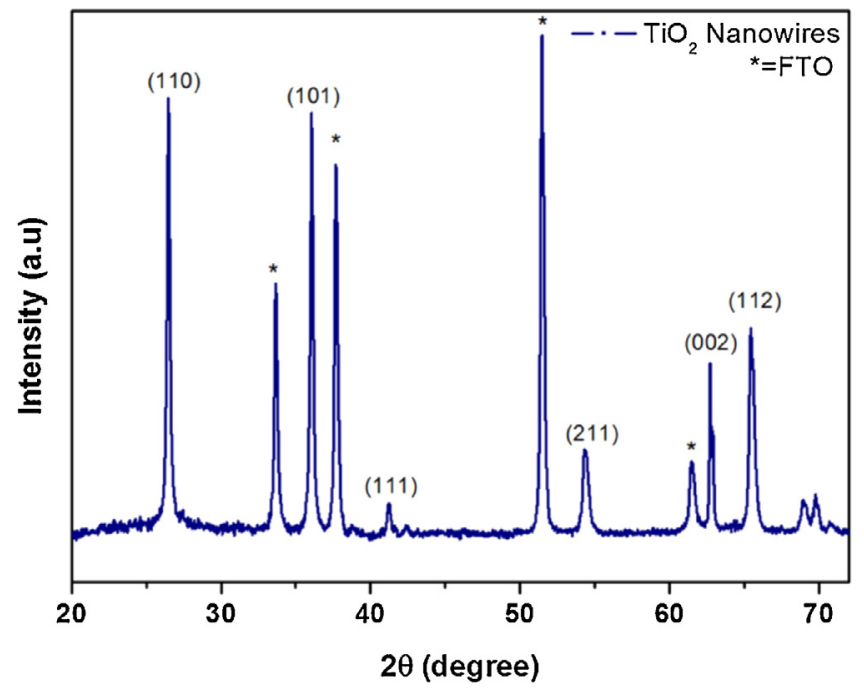

Fig. 4. XRD patterns of $\mathrm{ZnO}$ coated $\mathrm{TiO}_{2} \mathrm{NWs}$
Co and used as received. FTO coated glass ( $7 \Omega$ sq-1), Iodalyte HI electrolyte are all purchased from Solaronix.

\subsection{Growth of $\mathrm{TiO}_{2}$ nanowire array}

We prepared the uniform $\mathrm{TiO}_{2}$ NWs on FTO coated glass by hydrothermal technique according to our previous report $[17,18]$. Briefly, $\mathrm{HCl}(20 \mathrm{ml})$ and $\mathrm{DI}(20 \mathrm{ml})$ are mixed in a teflon-lined stainless steel autoclave $(45 \mathrm{ml})$ for $10 \mathrm{~min}$ and afterward $0.8 \mathrm{ml}$ titanium butoxide is added. After mixing with precursor for $30 \mathrm{~min}$, FTO is immersed into solution and kept at $140^{\circ} \mathrm{C}$ for 4 hours.

\subsection{Deposition of $\mathrm{ZnO}$ and Si layers on $\mathrm{TiO}_{2}$ nanowires}

NWs are coated with ZnO by ALD reactor. The substrate temperature is kept at $250^{\circ} \mathrm{C}$ during the process. Various samples are prepared with different number of cycles (1,2 and 3) of $\mathrm{ZnO}$ as an ultrathin layer on $\mathrm{TiO}_{2} \mathrm{NWs}$. For $\mathrm{ZnO}$ deposition by ALD, diethylzinc $\left(\left(\mathrm{C}_{2} \mathrm{H}_{5}\right)_{2} \mathrm{Zn}\right.$ or DEZn, Sigma-Aldrich) and HPLC-grade water $\left(\mathrm{H}_{2} \mathrm{O}\right)$ are used as the zinc and oxygen precursors, respectively. A thin layer of p-type $\alpha$-Si is deposited on prepared

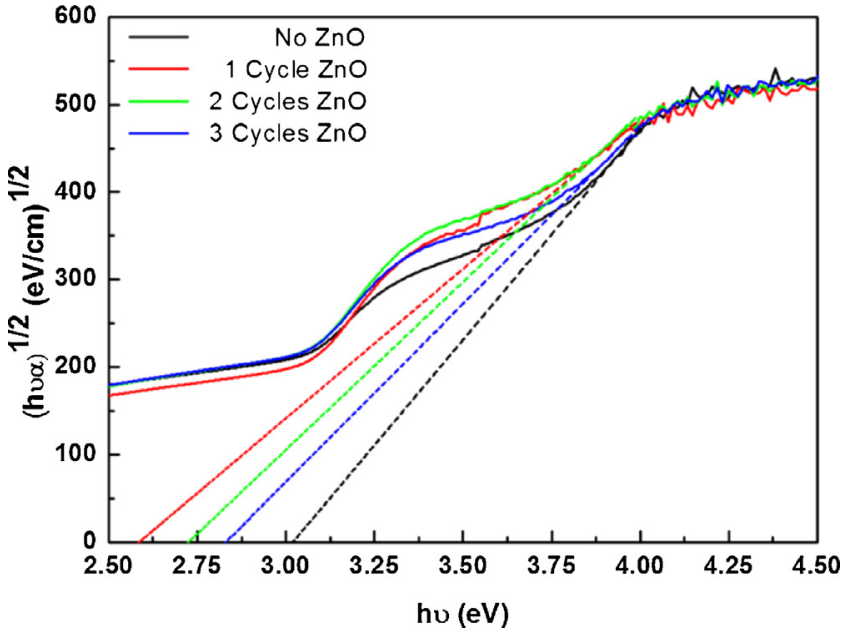

Fig. 5. $(\alpha \mathrm{h} v)^{1 / 2}$ versus $\mathrm{h} v$ plot for $\mathrm{TiO} 2 / \mathrm{ZnO}$ core-shell heterostructures with different $\mathrm{ZnO}$ cycles. 
Table 1

Effective optical band gap of $\mathrm{TiO}_{2} / \mathrm{ZnO}$ core-shell heterostructures.

\begin{tabular}{ll}
\hline$\#$ of $\mathrm{ZnO}$ & Band gap $(\mathrm{eV})$ \\
ALD cycles & \\
\hline 0 & 3.02 \\
1 & 2.58 \\
2 & 2.72 \\
3 & 2.83 \\
\hline
\end{tabular}

$\mathrm{TiO}_{2} / \mathrm{ZnO}$ core-shell NWs by RF magnetron sputter deposition system. The deposition of the $\alpha$-Si layer is carried out under $10^{-3}$ Torr Ar gas pressure employing $100 \mathrm{~W}$ RF power with a deposition rate of $0.3 \AA / s$ for 10 mins.

\subsection{Materials characterization}

Scanning electron microscope (SEM, FEI-Quanta 200 FEG) and transmission electron microscope (TEM, FEI model Tecnai G2 F30) are used to investigate the morphology and dimensions of the NWs. The phase structures of the obtained samples were identified using a Pananalytical (X'pert Pro MPD) instrument and XRD patterns were collected over the $2 \theta$ angular range of $20-70^{\circ}$ using Bragg-Brentano geometry. High resolution X-Ray photoelectron spectroscopy (XPS) measurement is performed to verify the existence of ultrathin $\mathrm{ZnO}$ layer.

\subsection{Device Assembly}

3D schematic of the $\alpha-\mathrm{Si} / \mathrm{ZnO} / \mathrm{TiO}_{2}$ heterojunction (HJ) solar cell structure is shown in Fig. 1. The proposed structure consists of 5 main parts; 1 ) hydrothermally grown $\mathrm{TiO}_{2}$ NWs on FTO coated glass, 2) ALD deposited $\mathrm{ZnO}$ layer coated on $\mathrm{TiO}_{2} \mathrm{NWs}, 3$ ) a thin layer of $\alpha-\mathrm{Si}$ deposited by $\mathrm{RF}$ magnetron sputtering on $\mathrm{TiO}_{2} / \mathrm{ZnO} \mathrm{HJ}$ as absorbing layer, 4) redox electrolyte iodide/triiodide based electrolyte $\left(\mathrm{I}^{-} / \mathrm{I}^{3-}\right)$ as a hole transfer mediator and finally 5) Pt-coated conducting glass as a counter electrode. For device assembly, the Si-coated $\mathrm{TiO}_{2} / \mathrm{ZnO}$ photoanode and platinum counter electrode are sandwiched together using a cell holder. The internal space of device is filled with $1 \mathrm{ml}$ syringe electrolyte through the backfilling technique (see Fig. 1). The area of the electrode is controlled using a mask of $0.20 \mathrm{~cm}^{2}$ area.

\section{Results and discussion}

Fig. 2 shows SEM and TEM images of fabricated ZnO coated NWs. Fig. 2 (a-c) illustrates that densely-packed NWs with an average length of $0.9-1.6 \mu \mathrm{m}$ have a diameter in the order of $80-150 \mathrm{~nm}$. The selected area electron diffraction (SAED) pattern and high resolution TEM (HRTEM) images provide further confirmation on single crystalline phase of each individual $\mathrm{TiO}_{2}$ NW. According to the HRTEM image, the lattice fringe spacing for the sample is $3.25 \mathrm{~A}^{\circ}$ which corresponds to the interspacing of the family of the (110) planes of tetragonal rutile phase of $\mathrm{TiO}_{2}$ and shows a direction growth occurred along the [001]. In addition to this, high resolution XPS measurement is performed to verify the existence of ultrathin ZnO layer (it is difficult to distinguish this angstrom-scale shell layer from $\mathrm{TiO}_{2} \mathrm{NW}$ core in TEM image). The spectrum of $\mathrm{TiO}_{2}$ and $\mathrm{ZnO}$ peaks including $\mathrm{Ti} 2 \mathrm{p}^{3 / 2}, \mathrm{Ti}_{2} \mathrm{p}^{1 / 2}$ and $\mathrm{Zn} 2 \mathrm{p}^{3 / 2}, \mathrm{Zn} 2 \mathrm{p}^{1 / 2}$ peaks are observed at $458.61 \mathrm{eV}, 464.26 \mathrm{eV}$ and $1022.18 \mathrm{eV}$ and 1045.24 (as depicted in Fig. 3(a,b)) which is in line with previous reports [19-21]. Finally, to explore the orientation of the NWs growth and their crystalline structure, XRD analysis is carried out on the obtained samples. The XRD pattern for the bare $\mathrm{TiO}_{2}$ NWs array is depicted in Fig. 4. All diffraction peaks are attributed to the FTO and rutile phase of $\mathrm{TiO}_{2}$. According to data shown here, the diffraction peaks pattern is in agreement with rutile phase of $\mathrm{TiO}_{2}$ with a dominant peak located at $36.25^{\circ}$ belongs to NWs grown along (101) direction. Since the shell layer is ultrathin, we observed no peak related to $\mathrm{ZnO}$.

As the first step in the optical characterization of the NWs, using transmission data obtained from UV-VIS-NIR spectrophotometer, optical band gap, $\mathrm{E}_{\mathrm{g}}$, is experimentally determined by extrapolating the linear portion of the Kubelka-Munk function, $(\alpha h v)^{1 / 2}$, versus photon energy, $h \nu$, graph shown in Fig. 5, where $\alpha$ is the absorption coefficient. Table 1 presents average optical band gap values calculated from the above. While the optical band gap of the bare rutile $\mathrm{TiO}_{2} \mathrm{NW}$ arrays is found to be $3.02 \mathrm{eV}$, that for $\mathrm{TiO}_{2} / \mathrm{ZnO}$ core-shell heterostructures with 1 cycle $\mathrm{ZnO}$, effective optical bad gap is reduced by $15 \%$ down to $2.58 \mathrm{eV}$. However, for thicker shell
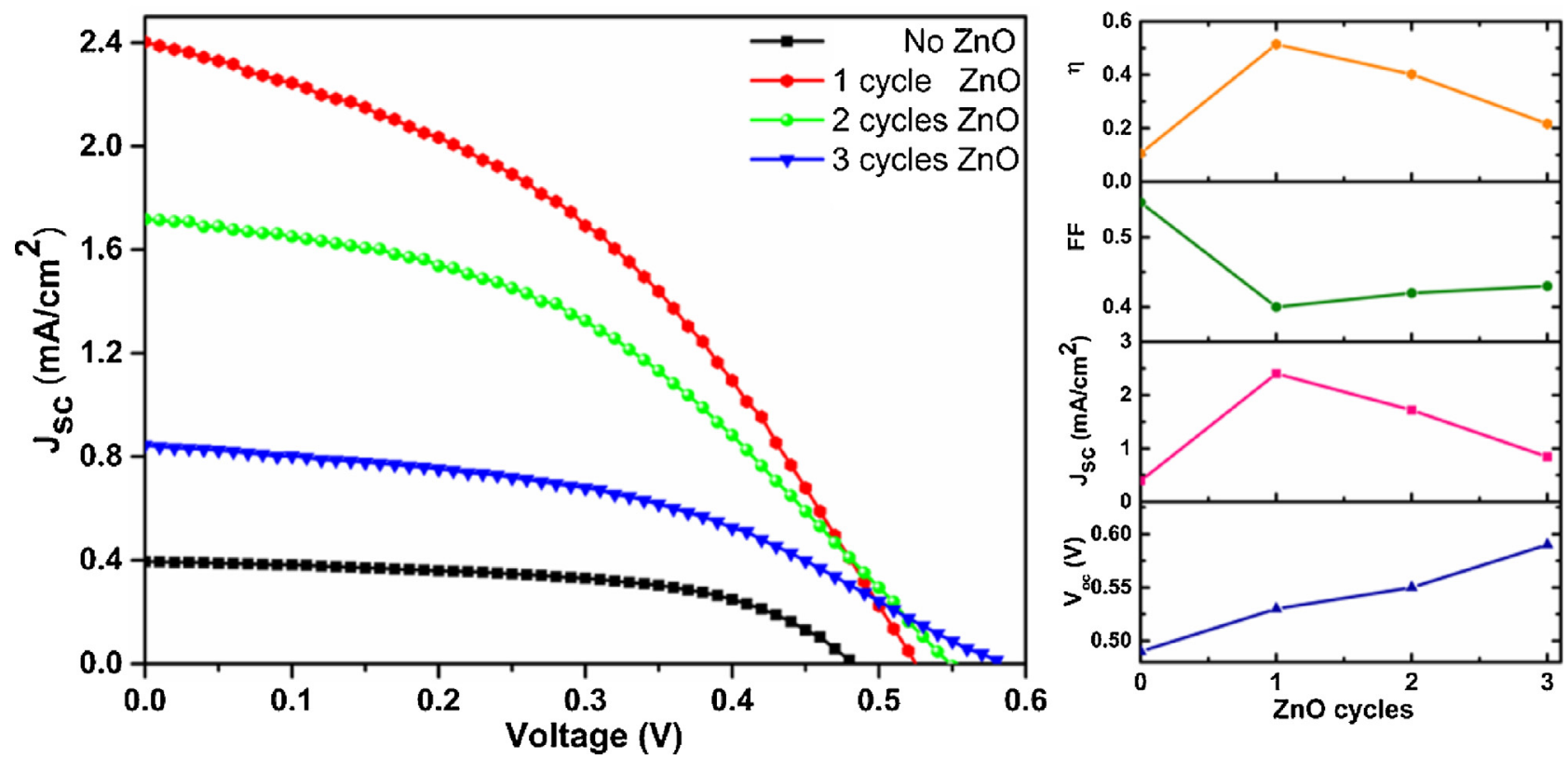

Fig. 6. (a) J-V characteristics and (b) Photovoltaic characteristics of solar cells for different $\mathrm{ZnO}$ cycles. 

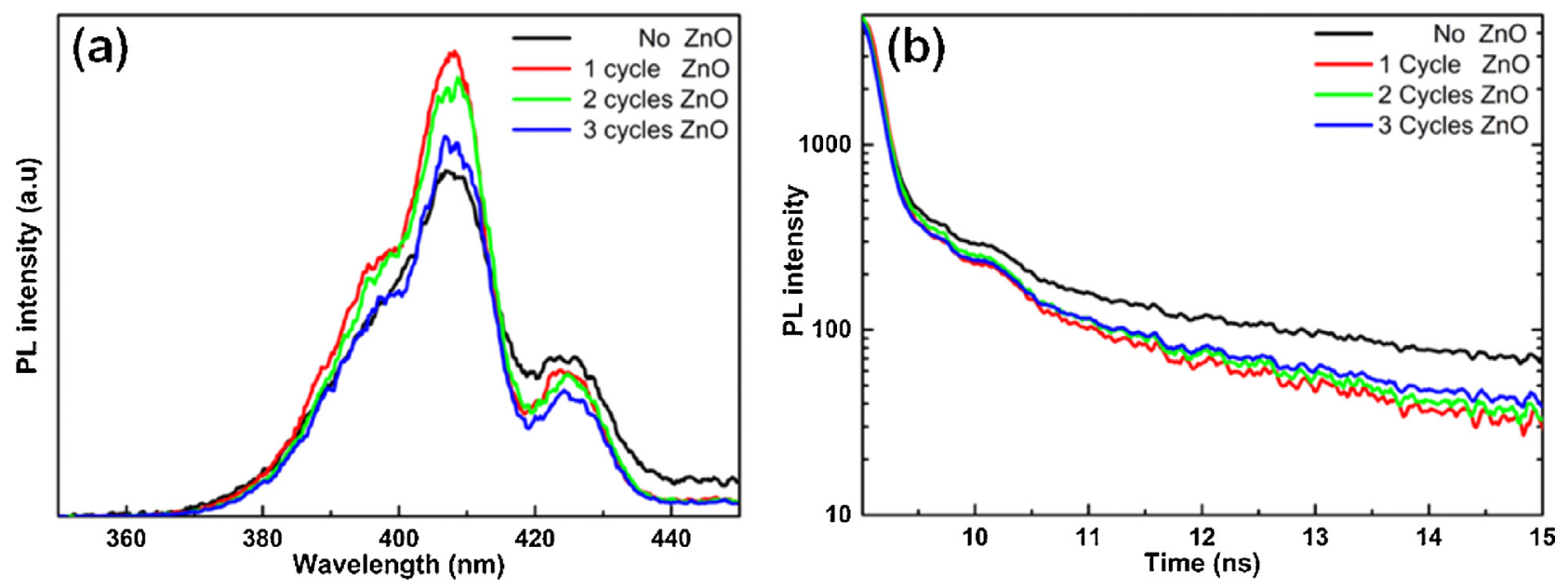

Fig. 7. Room temperature (a) PL spectra, (b) TRPL spectra for different ALD ZnO cycles coated samples

layers a gradual increase in band gap is followed in which for 3 cycles coated $\mathrm{ZnO}$ shell layer effective band gap reaches to $2.83 \mathrm{eV}$. This reduction in the band gap for first ALD cycles can be attributed to quantum confinement effect in the ultrathin $\mathrm{ZnO}$ shell. In upcoming sections it will be shown that band alignment of $\mathrm{TiO}_{2} / \mathrm{ZnO}$ interface is similar to type-II band alignment. Therefore, for ultrathin shells, a significantly reduced effective band gap results for exitonic transitions between valance band of $\mathrm{TiO}_{2}$ core and conduction band of $\mathrm{ZnO}$ shell layer. This reduced effective band gap is lower than those of both pure $\mathrm{TiO}_{2}$ and $\mathrm{ZnO}$. Moreover, this band gap narrowing and extension of the absorption edge toward higher wavelengths enable visible light driven photocatalytic and photoelectrochemical water splitting which is a hot research topic in recent years [14,22-24].

In order to investigate the impact of $\mathrm{ZnO}$ interfacial layer in the device PV performance, current-voltage $(\mathrm{J}-\mathrm{V})$ characteristics of different cells are measured by a Keithley 2440 source meter (AM1.5 G, $100 \mathrm{~mW} / \mathrm{cm}^{2}$ ). As it can be observed in Fig. 6(a), the number of $\mathrm{ZnO}$ cycles deposited on the $\mathrm{TiO}_{2}$ has a distinct effect on the performance of the solar cells. In the case of 1 ALD $\mathrm{ZnO}$ cycle, $\alpha-\mathrm{Si} / \mathrm{ZnO} / \mathrm{TiO}_{2} \mathrm{HJ}$ solar cell device efficiency makes a steep rise to a maximum efficiency of $0.514 \%$, which is nearly a five-fold increase compared to nominal efficiency of $0.106 \%$ for bare device (no $\mathrm{ZnO}$ interfacial layer). After the first cycle onwards, the efficiency starts to follow a decreasing trend down to $0.216 \%$ for 3 cycles. The trend associated to each critical PV parameter is shown in Fig. 6(b).
To scrutinize the physics behind this unprecedented change in device performance, a closer investigation of short circuit current $\left(J_{s c}\right)$ and open circuit voltage $\left(V_{o c}\right)$ trend is required. As it can be clearly seen, the $J_{s c}$ follows the same trend as efficiency $(\eta)$ while $V_{o c}$ shows a monotonically increasing trend from $0.49 \mathrm{~V}$ for the bare sample to $0.59 \mathrm{~V}$ for $3 \mathrm{ALD}$ cycles of $\mathrm{ZnO}$. Since the deposition of a sub-nanometer $\mathrm{ZnO}$ layer cannot change absorption considerably, this substantial improvement in PV parameters of the device can be attributed to reducing the loss mechanisms at the interface through reduction in density of trap states or retardation of recombination kinetics in the $\mathrm{HJ}$ interface.

According to the NWs hydrothermal growth method, insufficient Ti oxidization can induce surface dangling bonds such as oxygen vacancies or $\mathrm{Ti}$ interstitials which reduce the charge collection efficiency in the PV device. On the other hand, because of the self-limiting nature of the ALD technique, $\mathrm{ZnO}$ layer is expected to have few zinc interstitials and oxygen vacancies and in the meantime it passivates the traps on the $\mathrm{TiO}_{2}$ surface [25]. This is further investigated using photoluminescene (PL) spectroscopy since a correlation between the PL intensity and the defect densities are expected. Fig. 7(a) depicts the room temperature PL spectra of the bare and $\mathrm{ZnO}$-coated samples for an excitation wavelength of $320 \mathrm{~nm}$. A near-band-edge emission (NBE) at $408 \mathrm{~nm}$ and a shallow trap emission (STE) centered at $424 \mathrm{~nm}$ can be shown for all samples which is consistent with previous reports [26]. Following the deposition of only a single ALD cycle of
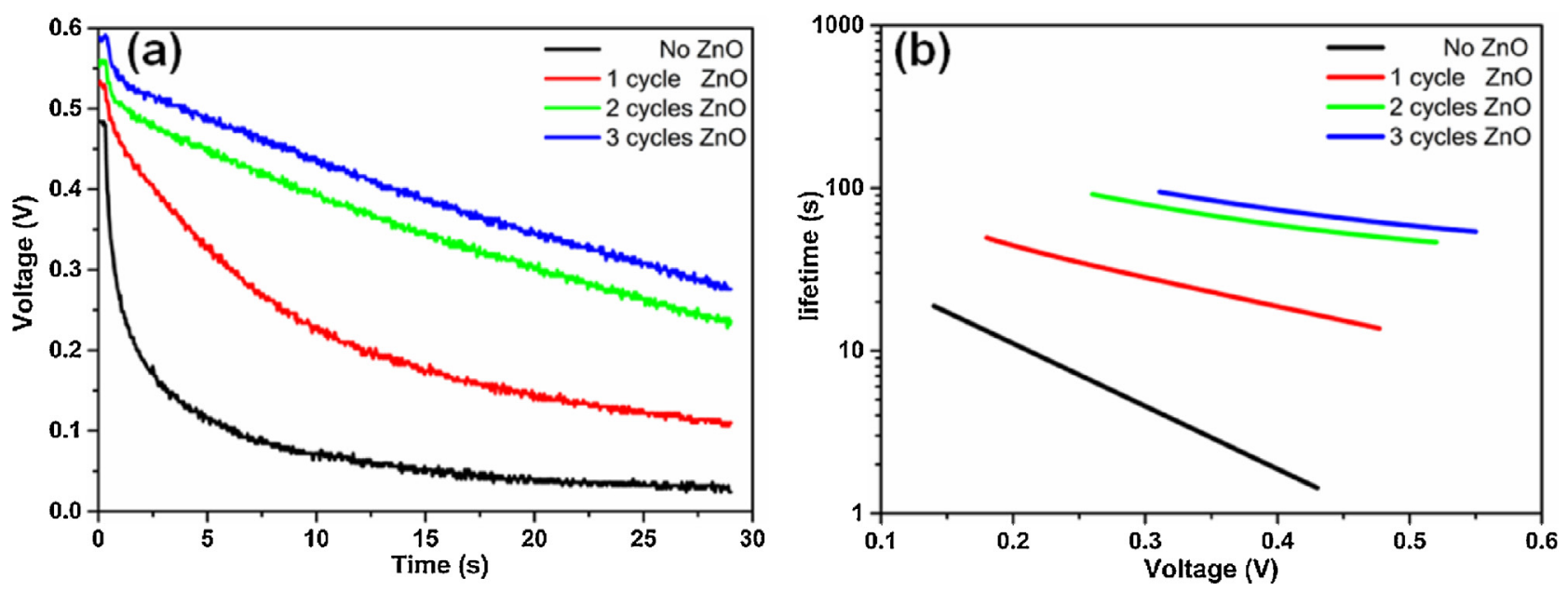

Fig. 8. (a) Experimental $V_{o c}$ decay and (b) determined carrier lifetimes for different ALD ZnO cycles coated samples 
ZnO layer, NBE increases considerably while STE is quenched compared to that of bare $\mathrm{TiO}_{2} \mathrm{NWs}$. For the next ALD cycles both peaks exhibit decreasing trends. These results reveal that the first ALD ZnO cycle will effectively terminate surface trap states on the NWs surface and suppress the activity of non-radiative recombination sites which in turn increases the NBE intensity together with quenching the STE $[27,28]$. To get further insight into the carrier dynamics, the room temperature time-resolved photoluminescence (TRPL) measurements for bare and passivated samples are conducted (Fig. 7(b)). As it is expected, all coated samples show faster decays than the bare one which is in agreement with previous results which reveals the passivation of surface traps via coating with ZnO layer. It is worthy to note that by moving to thicker layers, the photoexcited carriers show more long-lived behavior. In upcoming sections, it will be shown that energy bands across $\mathrm{TiO}_{2} / \mathrm{ZnO}$ interface are aligned in a way that an efficient charge separation can be provided in which photo excited electrons will diffuse to the shell layer while holes will be confined in the core. These results can also explain the reduction in NBE intensity for thick $\mathrm{ZnO}$ layers in which this charge separation at the $\mathrm{HJ}$ interface reduces the probability of band-to-band recombination and consequently lessens NBE intensity.
To probe recombination kinetics in complete PV device, $V_{\mathrm{oc}}$ decay, as a powerful measurement tool to estimate electron lifetime, is utilized. For this, we monitored the transient $V_{\text {oc }}$ as a function of time upon switching off the light to investigate the electron recombination kinetics. As it can be clearly seen in Fig. 8(a), HJ solar cell with no interfacial ZnO layer exhibits a sharp decay. However, the $V_{\text {oc }}$ of the $\mathrm{ZnO}$ passivated solar cells demonstrates much slower decay rates which imply slower recombination kinetics and longer electron lifetime for the excited electrons. The decay rate can be directly related to the electron lifetime by Eq. (1).

$\tau_{n}=-\frac{k T}{e}\left(\frac{d V_{o c}}{d t}\right)^{-1}$

The charge lifetimes determined from the $V_{\text {oc }}$ decay measurements are shown in Fig. 8(b). From this, it is clear that by deposition of just one cycle of $\mathrm{ZnO}$ layer charge lifetime has increased and this enhancement is continued for two cycle coated $\mathrm{ZnO}$ layer but after this point results are almost similar for two and three cycles. These results prove that, together with passivation of surface traps, this ultrathin $\mathrm{ZnO}$ embedded layer can also reduce recombination rate via providing an efficient charge separation at
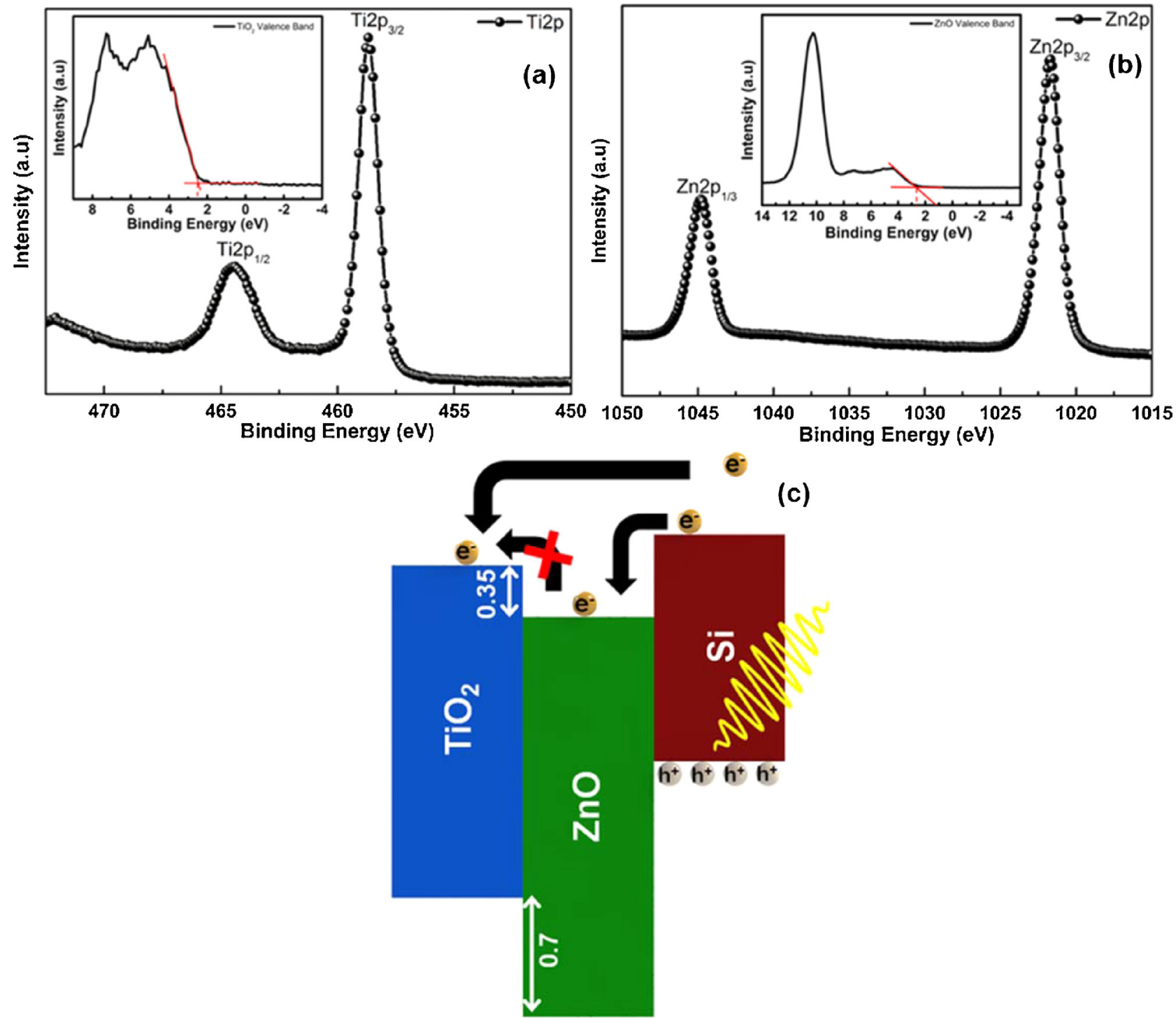

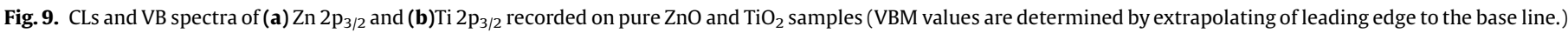
(c) experimentally determined energy band alignment for the $\mathrm{HJ}$. 
Table 2

Results obtained from XPS valence band spectra

\begin{tabular}{llc}
\hline Sample & Region & Binding Energy (eV) \\
\hline $\mathrm{TiO}_{2}$ & $\mathrm{Ti} 2 \mathrm{p}^{3 / 2}$ & 458.68 \\
& $\mathrm{VBM}$ & 2.59 \\
$\mathrm{ZnO}$ & $\mathrm{Zn} 2 \mathrm{p}^{3 / 2}$ & 1021.58 \\
& $\mathrm{VBM}$ & 2.62 \\
$\mathrm{TiO}_{2} / \mathrm{ZnO}$ & $\mathrm{Zn} 2 \mathrm{p}^{3 / 2}$ & 1022.18 \\
& $\mathrm{Ti} 2 \mathrm{p}^{3 / 2}$ & 458.61 \\
\hline
\end{tabular}

the interface. Despite of its excellent PV characteristics, this coreshell structure has a great potential for photoelectrochemical water splitting due to having low recombination rates, better carrier separation and high collection capability which are prominent factors for hydrogen production rate of water splitting cell [29-32].

As shown earlier, deposition of one cycle $\mathrm{ZnO}$ embedded layer boosts power conversion efficiency up to its maximum and moving toward thicker layers, efficiency gradually falls down. In order to explore the physics behind this drop in device performance, understanding the electron injection mechanism at $\mathrm{HJ}$ interface is an imperative task. Although some reports show a band alignment where the position of conduction band of the $\mathrm{ZnO}$ layer is at higher energy than that of $\mathrm{TiO}_{2}$ [33-35], some other reports claim the opposite [36,37]. For this aim, an analysis technique of Kraut [38] based on high resolution XPS measurement is adopted to provide band alignment in $\mathrm{TiO}_{2} / \mathrm{ZnO}$ heterostructure via estimating valance and conduction band offsets $\left(\Delta E_{V}\right.$ and $\left.\Delta E_{C}\right)$. Firstly, the energy difference between $\mathrm{Zn} 2 \mathrm{p}$ and Ti2p core levels $\left(\Delta E_{C L}\right)$ in the $\mathrm{TiO}_{2} / \mathrm{ZnO}$ core-shell sample is found to be $563.57 \mathrm{eV}$ Fig. 3. Also, the difference between core level energy and valance band maximum, $\left(\Delta E_{C L}-\Delta E_{V B M}\right)$ for both $\mathrm{TiO}_{2} \mathrm{NWs}$ sample and $\mathrm{ZnO}$ thin film layer is calculated as it is illustrated in Fig. 9(a,b). Table 2 summarizes all obtained data. Moreover, the optical band gap for $\mathrm{TiO}_{2} \mathrm{NW}$ array has been estimated to be $3.02 \mathrm{eV}$ using transmission data obtained from UV-VIS-NIR spectrophotometer and extrapolating the linear portion of the Kubelka-Munk function, see Fig. 5. For this analysis, the band gap for $\mathrm{ZnO}$ is taken as $3.37 \mathrm{eV}$ from our previous work [39]. Finally, employing Eqs. (2) and (3) the amounts of $\Delta E_{V}$ and $\Delta E_{C}$ are calculated to be $0.7 \mathrm{eV}$ and $0.35 \mathrm{eV}$, respectively.

$\Delta E_{V}=\left(E_{C L}-E_{V B M}\right)_{T_{i O}{ }_{2} N W}-\left(E_{C L}-E_{V B M}\right)_{b u l k Z n O}+\Delta E_{C L}$

$\Delta E_{C}=\left(E_{g_{\text {Zno }}}-E_{g_{\mathrm{TiO}_{2}}}-\Delta E_{V}\right)_{\mathrm{TiO}_{2} / \text { ZnOcore-shell }}$

This analysis suggests a band alignment depicted in Fig. 9(c). As it can be seen from the schematic, conduction band offset in $\mathrm{TiO}_{2} /$ $\mathrm{ZnO}$ interface is in a way that, a portion of photo generated electrons in the absorbing layer will be captured by $\mathrm{ZnO}$ quantum well while injecting into $\mathrm{TiO}_{2}$ conduction band. This probability is intensified by increasing the width of $\mathrm{ZnO}$ quantum well which in turn leads to a reduction in the PV efficiency of the device.

\section{Conclusions}

In summary, we demonstrated that using angstrom-thick atomic layer deposited $\mathrm{ZnO}$ shell layer can significantly enhance the power conversion efficiency of PV devices based on $\mathrm{TiO}_{2} \mathrm{NWs}$. Such an ultrathin layer contributes to device performance enhancement via reducing the recombination mechanisms in the interface without significantly impeding the injection of photo-generated carriers due to its negligible thickness. This improvement, however, is independent of the type of absorbing layer ( $\alpha$-Si is used here for proof-ofconcept purpose). The results presented here are considered a paradigm shift not only in NW-based PV technologies but also in other photoelectrochemical and photocatalytic applications and serve as a beacon for future performance enhanced NW-based all$\mathrm{TiO}_{2}$ solar cell and water splitting devices.

\section{ACKNOWLEDGEMENTS}

This work was supported by the Scientific and Technological Research Council of Turkey (TUBITAK), grant numbers 109E044,112M004, 112E052, and 113M815. A.K.O. acknowledges support from the Turkish Academy of Sciences Distinguished Young Scientist Award (TUBA GEBIP).

\section{References}

[1] X. Feng, K. Shankar, O.K. Varghese, M. Paulose, T.J. Latempa, C. Grimes, Vertically Aligned Single Crystal $\mathrm{TiO}_{2}$ Nanowire Arrays Grown Directly on Transparent Conducting Oxide Coated Glass: Synthesis Details and Applications, Nano Lett. 8 (2008) 3781.

[2] B.E. Hardin, H.J. Snaith, M.D. McGehee, The renaissance of dye-sensitized solar cells, Nat. Photonics 6 (2012) 162.

[3] H. Hoppe, H. Sariciftci, Organic solar cells: An overview, J. Mater. Res. 19 (2011) 1924.

[4] M. Seol, H. Kim, Y. Tak, K. Yong, Novel nanowire array based highly efficient quantum dot sensitized solar cell, Chem. Commun. (Camb). 46 (2010) 5521.

[5] Y. Tak, S.J. Hong, J.S. Lee, K. Yong, Fabrication of $\mathrm{ZnO} / \mathrm{CdS}$ core/shell nanowire arrays for efficient solar energy conversion, J. Mater. Chem. 19 (2009) 5945.

[6] Y. Tang, X. Hu, M. Chen, L. Luo, B. Li, L. Zhang, CdSe nanocrystal sensitized ZnO core-shell nanorod array films: Preparation and photovoltaic properties, Electrochim. Acta 54 (2009) 2742.

[7] K.S. Leschkies, R. Divakar J. Basu, E. Enache-Pommer, JE. Boercker, C.B. Carter, U.R. Kortshagen, D.J. Norris, E.S. Aydil, Photosensitization of ZnO Nanowires with CdSe Quantum Dots for Photovoltaic Devices, Nano Lett. 7 (2007) 1793.

[8] X. Wang, R. Liu, T. Wang, B. Wang, Y. Xu, H. Wang, Dual Roles of ZnS Thin Layers in Significant Photocurrent Enhancement of $\mathrm{ZnO} / \mathrm{CdTe}$ Nanocable Arrays Photoanode, ACS Appl. Mater. Interfaces 5 (2013) 3312-33161.

[9] G. Zhang, S. Jiang, Y. Lin, W. Ren, H. Cai, Y. Wu, Q. Zhang, N. Pan, Y. Luo, X. Wang, $\mathrm{J}$. Improving the photovoltaic performance of solidstate $\mathrm{ZnO} / \mathrm{CdTe}$ core-shell nanorod array solar cells using a thin CdS interfacial layer, Mater. Chem. A 2 (2014) 5675.

[10] X. Wang, H. Zhu, Y. Xu, H. Wang, Y. Tao, S. Hark, X. Xiao, Q. Li, Aligned ZnO/CdTe CoreShell Nanocable Arrays on Indium Tin Oxide: Synthesis and Photoelectrochemical Properties, ACS Nano 4 (2010) 3302-3308.

[11] J. Jean, S. Chang, P.R. Brown, J.J. Cheng, P.H. Rekemeyer, M.G. Bawendi, S. Gradečak, V. Bulović, ZnO Nanowire Arrays for Enhanced Photocurrent in PbS Quantum Dot Solar Cells, Adv. Mater. 25 (2013) 2790.

[12] X. Li, J. Yu, J. Low, Y. Fang, J. Xiao, X. Chen, Engineering heterogeneous semiconductors for solar water splitting, J Mater Chem A 48 (2014).

[13] R. Liu, Z. Zheng, J. Spurgeon, X. Yang, Enhanced photoelectrochemical watersplitting performance of semiconductors by surface passivation layers, Energy Environ Sci 7 (2504) (2014).

[14] M. Ni, M.K.H. Leung, D.Y.C. Leung, K. Sumathy, A review and recent developments in photocatalytic water-splitting using $\mathrm{TiO}_{2}$ for hydrogen production, Renew Sustain Energy Rev 11 (2007) 401.

[15] A.K. Chandiran, N. Tetreault, R. Humphry-Baker, F. Kessler, E. Baranoff, C. Yi, M. K. Nazeeruddin, M. Grätzel, Subnanometer $\mathrm{Ga}_{2} \mathrm{O}_{3}$ Tunnelling Layer by Atomic Layer Deposition to Achieve $1.1 \mathrm{~V}$ Open-Circuit Potential in Dye-Sensitized Solar Cells, Nano Lett. 12 (2012) 3941.

[16] T.C. Li, S. Go, F. Fabregat-santiago, J. Bisquert, P.R. Bueno, C. Prasittichai, J.T. Hupp, T.J. Marks, Surface Passivation of Nanoporous $\mathrm{TiO}_{2}$ via Atomic Layer Deposition of $\mathrm{ZrO}_{2}$ for Solid-State Dye-Sensitized Solar Cell Applications, J. Phys. Chem. C 14 (2009) 18385.

[17] M. Ghaffari, M. Burak Cosar, Halil I. Yavuz, M. Ozenbas, Ali K. Okyay, Effect of Au nano-particles on $\mathrm{TiO}_{2}$ nanorod electrode in dye-sensitized solar cells, Electrochim. Acta 58 (2011) 19-24.

[18] T.G. Ulusoy, A. Ghobadi, A.K. Okyay, Surface engineered angstrom thick ZnOsheathed $\mathrm{TiO}_{2}$ nanowires as photoanodes for performance enhanced dyesensitized solar cells, J. Mater. Chem. A 2 (2014) 16867.

[19] S.-C. Li, S.-C. Diebold, Reactivity of $\mathrm{TiO}_{2}$ Rutile and Anatase Surfaces toward Nitroaromatics, J. Am. Chem. Soc. 132 (2010) 64.

[20] M. Andersson, M. Lars, Preparation of Nanosize Anatase and Rutile $\mathrm{TiO}_{2}$ by Hydrothermal Treatment of Microemulsions and Their Activity for Photocatlytic Wet Oxidation of Phenol, J. Phys. Chem. B 106 (2002) $10674-10679$.

[21] S. Kwon, S. Bang, S. Lee, S. Jeon, W. Jeong, H. Kim, S.C. Gong, H.J. Chang, H. Park, $\mathrm{H}$. Jeon, Characteristics of the $\mathrm{ZnO}$ thin film transistor by atomic layer deposition at various temperatures, Semicond. Sci. Technol. 24 (2009) 035015.

[22] D. Ramírez-Ortega, A.M. Meléndez, P. Acevedo-Peña, I. González, R. Arroyo, Semiconducting properties of $\mathrm{ZnO} / \mathrm{TiO}_{2}$ composites byelectrochemical measurements and their relationship with photocatalytic activity, Electrochim Acta 140 (2014) 541. 
[23] L. Tsui, G. Zangari, Modification of $\mathrm{TiO}_{2}$ nanotubes by $\mathrm{Cu}_{2} \mathrm{O}$ for photoelectrochemical, photocatalytic, and photovoltaic devices, Electrochimica Acta 128 (2014) 341.

[24] Z. Fu, T. Jiang, Z. Liu, D. Wang, L. Wang, T. Xie, Highly photoactive Ti-doped $-\mathrm{Fe}_{2} \mathrm{O}_{3}$ nanorod arrays photoanodeprepared by a hydrothermal method for photoelectrochemical water splitting, Electrochim Acta 129 (2014) 358.

[25] Z.W. Ai, Y. Wu, H. Wu, T. Wang, C. Chen, Y. Xu, C. Liu, Enhanced band-edge photoluminescence from $\mathrm{ZnO}$-passivated $\mathrm{ZnO}$ nanoflowers by atomic layer deposition, Nanoscale Res. Lett. 8 (2013) 105.

[26] S. Mathew, A.K. Prasad, T. Benoy, P.P. Rakesh, M. Hari, T.M. Libish, P. Radhakrishnan, V.P.N. Nampoori, C.P.G. Vallabhan, UV-Visible Photoluminescence of $\mathrm{TiO}_{2}$ Nanoparticles Prepared by Hydrothermal Method, J. Fluoresc. 22 (2012) 1563.

[27] M.K. Nowotny, L.R. Sheppard, T. Bak, T. Nowotny, Defect chemistry of titanium dioxide: application of defect engineering in processing $\mathrm{TiO}_{2}$-based photocatalysts, J. Phys. Chem. C 112 (2008) 5275-5300.

[28] G. Liu, F. Li, D.-W. Wang, D.-M. Tang, C. Liu, X. Ma, G.Q. Lu, H.-M. Cheng, Electron field emission of a nitrogen-doped $\mathrm{TiO}_{2}$ nanotube array, Nanotechnology 19 (2008) 025606.

[29] D. Wang, X. Zhang, P. Sun, S. Lu, L. Wang, C. Wang, Y. Liu, Photoelectrochemical Water Splitting with Rutile $\mathrm{TiO}_{2}$ Nanowires Array: Synergistic Effect of Hydrogen Treatment and Surface Modification with Anatase Nanoparticles, Electrochim Acta 130 (2014) 290.

[30] H. Ali, N. Ismail, A. Hegazy, M. Mekewi, A novel photoelectrode from $\mathrm{TiO}_{2}-\mathrm{WO}_{3}$ nanoarrays grown on FTO for solar water splitting, Electrochim Acta 150 (2014) 314.
[31] S.H. Kang, S.-Y. Lee, M.G. Gang, K.-S. Ahn, J.H. Kim, Bifunctional Effects of CdSe Quantum Dots and $\mathrm{Nb}_{2} \mathrm{O}_{5}$ Interlayer for $\mathrm{ZnO}$ Nanorods-based Photoelectrochemical Water-Splitting Cells, Electrochim Acta 133

$$
\text { (2014) } 262 .
$$

[32] A. Kushwaha, M. Aslam, ZnS shielded $\mathrm{ZnO}$ nanowire photoanodes for efficient water splitting, Electrochim Acta 130 (2014) 222.

[33] K. Shen, K. Wu, D. Wang, Band alignment of ultra-thin hetero-structure ZnO $\mathrm{TiO}_{2}$ junction, Mater. Res. Bull. 51 (2014) 141.

[34] S. Xuhui, C. Xinglan, T. Wanquan, W. Dong, L. Kefei, Performance comparison of dye-sensitized solar cells by using different metal oxide- coated $\mathrm{TiO}_{2}$ as the photoanode, AIP Adv. 4 (2014) 31304.

[35] C. Cheng, A. Amini, C. Zhu, Z. Xu, H. Song, N. Wang, Enhanced photocatalytic performance of $\mathrm{TiO}_{2}$-ZnO hybrid nanostructures, Sci. Rep. 4 (2014) 4181.

[36] D. Kuang, S. Ito, B. Wenger, C. Klein, J.-E. Moser, R. Humphry-Baker, S.M. Zakeeruddin, M. Grätzel, High molar extinction coefficient heteroleptic ruthenium complexes for thin film dye-sensitized solar cells, J. Am. Chem. Soc. 128 (2006) 4146.

[37] R.A. Rakkesh, R.A. Balakumar, Facile synthesis of $\mathrm{ZnO} / \mathrm{TiO}_{2}$ core-shell nanostructures and their photocatalytic activities, J. Nanosci. Nanotechnol. 13 (2013) 370.

[38] E.A. Kraut, R.W. Grant, J.R. Waldrop, S.P. Kowalczyk, Semiconductor core-level to valence-band maximum binding-energy differences: Precise determination by X-ray photoelectron spectroscopy, Phys. Rev. B 28 (1983) 1965-1977.

[39] L.E. Aygun, F.B. Oruc, F.B. Atar, A.K. Okyay, Dynamic Control of Photoresponse in ZnO-Based Thin-Film Transistors in the Visible Spectrum, Photonics Journal, IEEE 5 (2013) 2200707-2200707. 